\title{
Knowledge, Attitude, and Practices Related to Cervical Cancer Among Adult Women in Azad Kashmir: A Hospital-based Cross-sectional Study
}

Arslaan Javaeed ${ }^{1}$, Sana Shoukat ${ }^{1}$, Saddaf Hina ${ }^{1}$, Zartasha Hameed $^{2}$, Sanniya Khan Ghauri ${ }^{3}$, Malik Mahmood Ahmed ${ }^{4}$

1. Pathology, Poonch Medical College, Rawalakot, PAK 2. Pathology, Sheikh Khalifa Bin Zayed Hospital, Rawalakot, PAK 3. Emergency Medicine, Shifa International Hospital, Islamabad, PAK 4. Pathology, Azad Jammu Kashmir Medical College, Muzzfarabad, PAK

Corresponding author: Arslaan Javaeed, arslaanjavaeed@yahoo.com

\section{Abstract \\ Objective}

To assess the knowledge, attitude, and practices (KAP) related to cervical cancer among the adult women of Azad Kashmir, Pakistan.

\section{Methods}

A cross-sectional study, involving 594 patients visiting the Gynecology and Obstetrics outpatient departments of Khalifa bin Zayed Hospital, Rawalakot, Azad Kashmir, Pakistan, was done. The study questionnaire (interviewer-administered) included 26 items to measure the knowledge, attitude, and practices related to cervical cancer and was formulated and validated with the help of gynecologists and epidemiologists. Descriptive statistics were used to present the knowledge, attitude, and practice level of respondents. The respondents' knowledge, attitude, and practice score was compared across gender and level of education. Data analysis was done using SPSS v 23.0 (IBM Corporation, Armonk, NY, US) at $95 \%$ CI.

\section{Results}

A total of 346 (58.2\%) women heard about cervical cancer and 210 (35.4\%) women heard about the pap smear test. Thirty-five women (5.9\%) underwent a pap smear test in their lifetime. More than half (51.7\%) thought that undergoing a pap smear test is embarrassing. But 382 respondents (64.3\%) will undergo a pap smear test if the test is provided free of cost. Unmarried women had a better KAP score as compared to married women $(13.58 \pm 5.14$ vs $9.12 \pm 4.04, \mathrm{p}<.001)$. The KAP score was significantly different in respondents with different levels of education $(\mathrm{p}<.001)$.

\section{Conclusion}

Received 03/02/2019

Review began 03/06/2019 Review ended 03/09/2019 Published 03/11/2019

๑) Copyright 2019

Javaeed et al. This is an open access article distributed under the terms of the Creative Commons Attribution License CC-BY 3.0., which permits unrestricted use, distribution, and reproduction in any medium, provided the original author and source are credited.
This study showed a better KAP score as compared to previous Pakistani studies but, still, there is plenty of room to improve. Women of developed countries have significantly better knowledge, attitude, and practices related to cervical cancer. Local authorities may run a free pap smear screening program in communities to detect cervical cancer early.

\section{Categories: Pathology}

Keywords: cervical cancer, pap smear, screening, adult women, pakistan

\section{Introduction}

Cervical cancer is the second most common cancer among women worldwide [1]. Eighty-six percent of all cervical cancer diagnosed and $88 \%$ of death due to cervical cancer occur in developing regions of the world [1-2]. Worldwide, there were approximately 493,243 new cases and 273,505 deaths attributed to cervical cancer in 2002, which is about one-tenth of total female cancer deaths [3]. The present exact rate of the incidence and prevalence of cervical cancer is not known in Pakistan because it is an ignored disease in terms of screening and prevention [4]. In 2002, the prevalence of cervical cancer in Pakistani women was $0.009 \%$ while in 2008 , it was $0.019 \%$, according to advance research started by the World Health Organization (WHO) [5].

As Pakistan is a developing country, human papillomavirus (HPV) is a major threat to public health. To date, HPV screening is generally not implemented in Pakistan. A major hurdle to the exact statistical assessment and evaluation of the HPV epidemic are social restrictions [6]. In Pakistan, to date, it is a taboo to discuss sexually transmitted diseases and sexual education, due to which most of the female population, mainly from the rural areas, have a poor understanding of sexually transmitted diseases (STDs) and gender-specific cancers. Perhaps due to this, cervical cancer caused by HPV is ranked the third major contributing source of 
For establishing successful strategies and increasing the utilization of preventive services, there is a need to explore the extent to which the general female population is aware of cervical cancer-related problems. And there is scanty information about the knowledge and awareness of Pakistani women on this potential issue. In this hospital-based study, we aim to assess the knowledge, attitude, and practices related to cervical cancer among adult Pakistani women.

\section{Materials And Methods}

A cross-sectional, interview-based study was conducted in the Gynecology and Obstetrics outpatient department (OPD), Sheikh Khalifa bin Zayed Hospital, Rawalkot, Azad Kashmir (CMH), from March to September 2018. As the current prevalence rate of cervical cancer in Pakistan was unknown, we calculated a minimum required sample size of 384 at the $95 \%$ confidence interval and prevalence of .05 . In order to get the required sample size, we have invited all Gynecology and Obstetrics OPD patients during the study period. A total of 594 patients gave consent and fully answered the questionnaire. The study questionnaire was developed with the help of gynecologists and epidemiologists of the Sheikh Khalifa bin Zayed Hospital. The questionnaire was checked for internal consistency. The questionnaire included baseline characteristics, cervical cancer-related knowledge, attitude, and practice sections (26 items). The purpose of the study was clearly stated to the respondents, and consent was secured. Ethical approval was taken from the ethical review committee of Sheikh Khalifa bin Zayed Hospital, Rawalkot, Azad Kashmir, Pakistan.

\section{Statistical analysis}

Baseline characteristics and cervical cancer KAP questions were presented as frequencies and percentages. The number of correct responses from each respondent was counted. The mean number of correct responses was compared across gender and education level by the independent samples t-test and one-way analysis of variance (ANOVA), respectively. Data were presented in tables and charts.

The analysis was performed at the 95\% confidence interval using the Statistical Package for Social Science (SPSS), version 23.0 (IBM, Armonk, NY, USA).

\section{Results}

The interviewer approached 700 Gynecology and Obstetrics OPD patients (adult women) with the study questionnaire; out of these 594 women gave consent and completely answered all the questions (response rate $84.85 \%$ ). The mean age of all respondent was $26.61 \pm 0.29$ years. Almost half of the respondents, 288 (48.5\%), were married and the rest were unmarried. The respondents' level of education was as follows: no formal education 51 (8.6\%), primary level 81 (13.6\%), secondary level 78 (13.1\%), higher secondary level 144 (24.2\%), and graduate level 240 (40.4\%).

More than one-third, 211 (35.5\%), respondents never heard of cervical cancer. Most of the women did not know about any of the symptoms of cervical cancer. More than half, 307 (51.7), thought that going for the pap smear test was embarrassing. Cervical cancer knowledge and attitude related to the three-point Likert scale questions and responses are presented in Table 1. 


\section{Cureus}

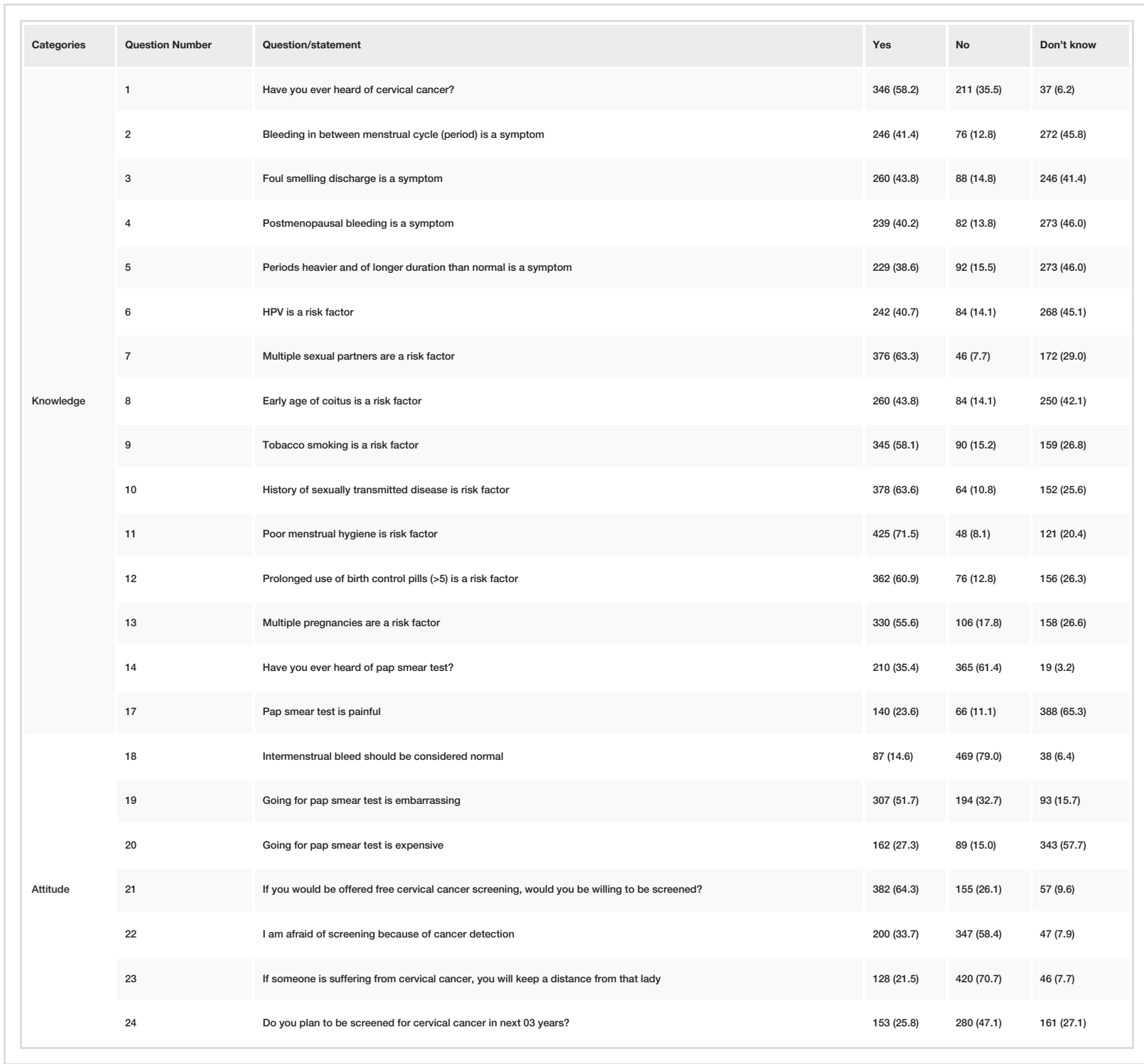

\section{TABLE 1: Responses to knowledge and attitude related to Likert-scale questions}

*Question nos. 15, 16, and practice-related questions (25 and 26) were not formulated on the Likert scale and were presented later.

Only $37.2 \%$ respondents knew the correct age of starting a pap smear test and $25.9 \%$ knew it should be done every three years. Only a handful of patients, 35 (5.9\%), underwent screening for cervical cancer in their lifetime and among them, only two respondents underwent the test within the last three years, as shown in Figures 1-4. 


\section{Cureus}

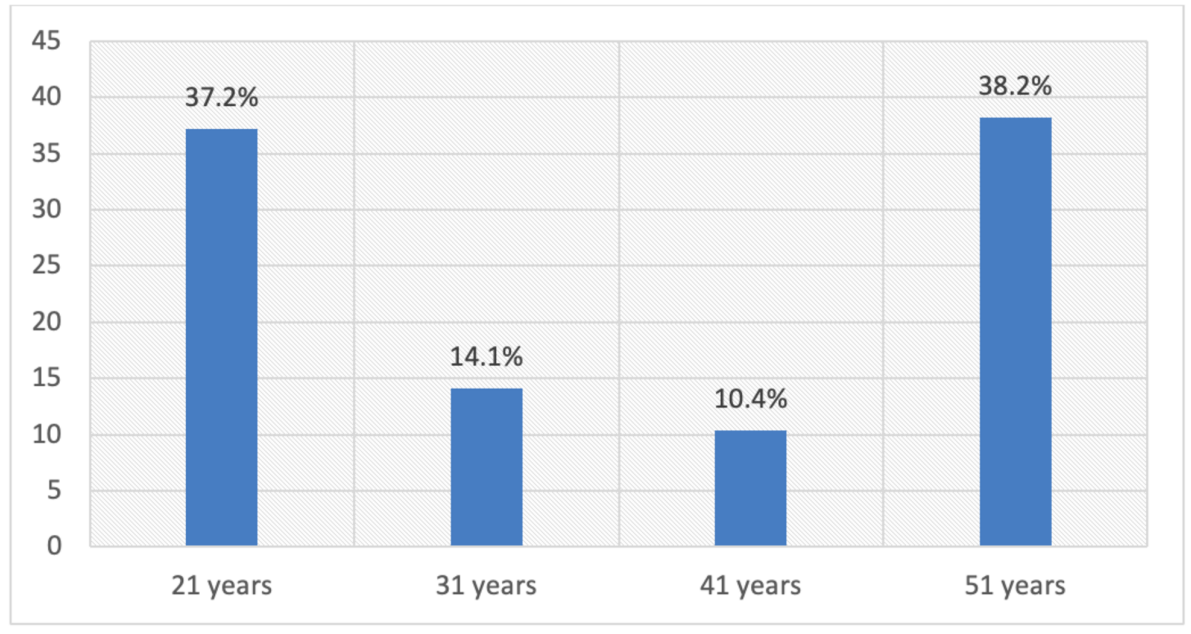

FIGURE 1: Distribution of respondents by knowledge regarding the correct age of starting a pap smear test

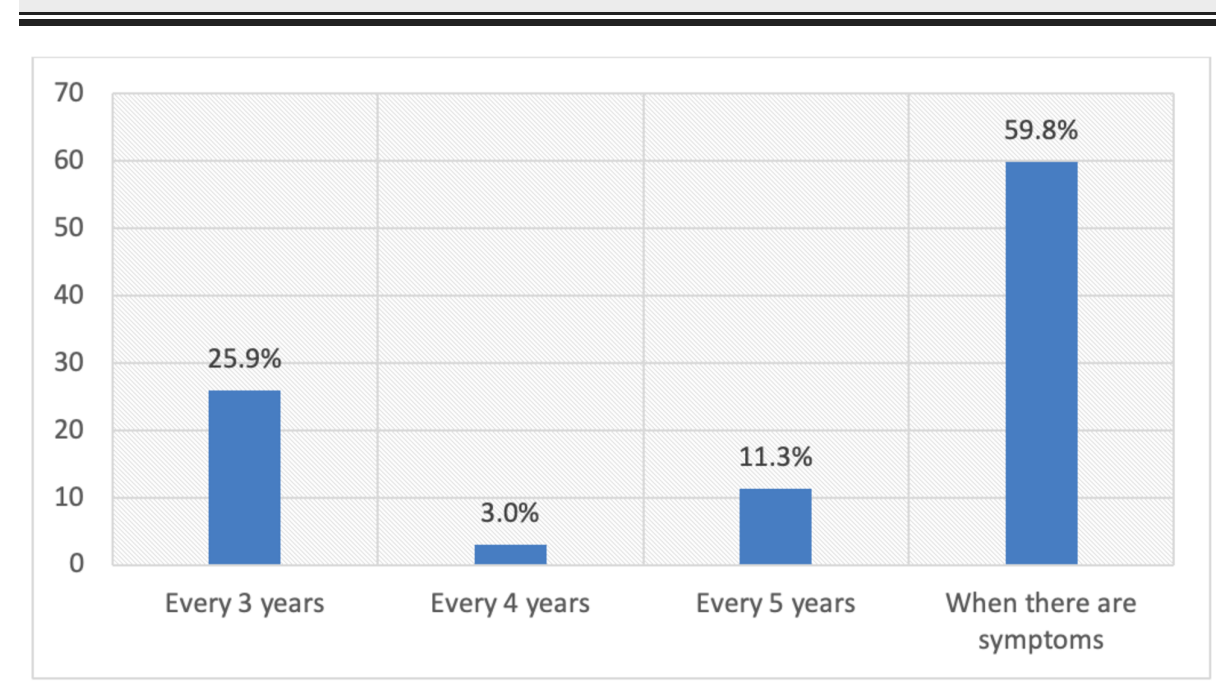

FIGURE 2: Distribution of respondents by knowledge regarding the frequency of the pap smear test

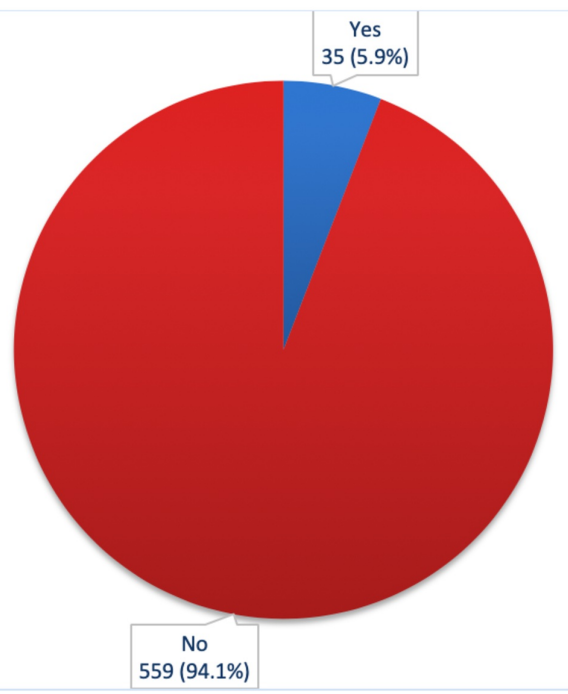




\section{Cureus}

FIGURE 3: Distribution of respondents who underwent screening for cervical cancer

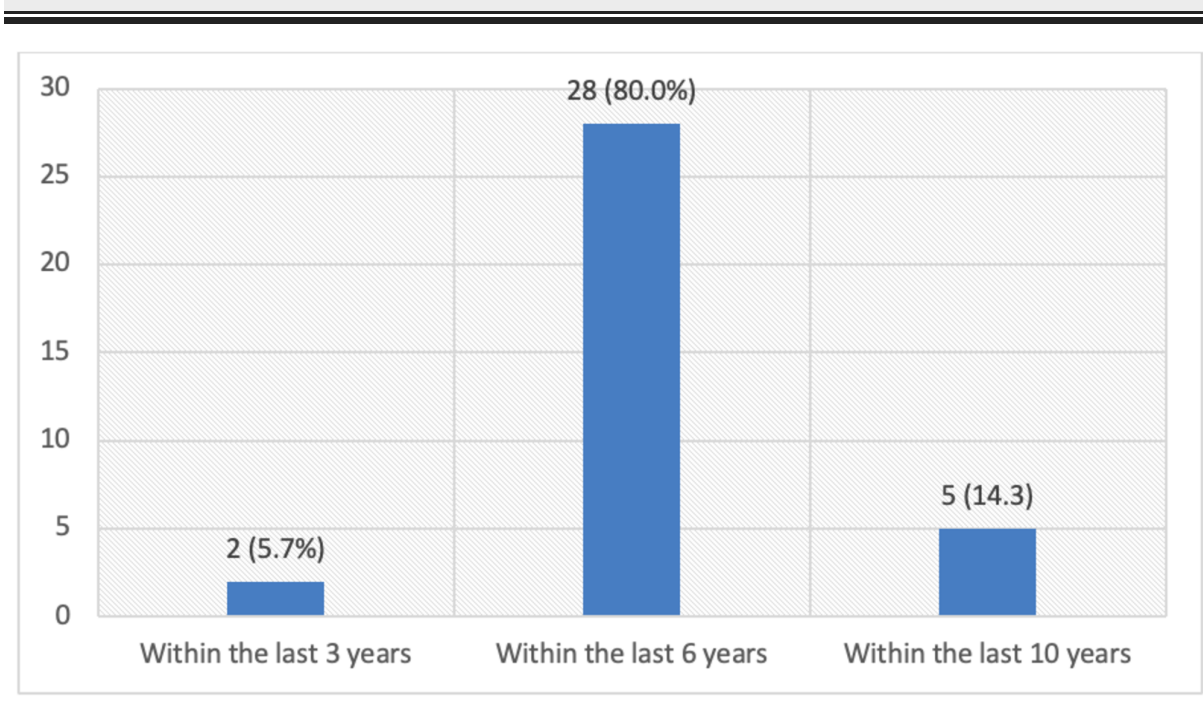

FIGURE 4: Distribution of respondents by the last time they were screened for cervical cancer $(n=35)$

Unmarried women had a better knowledge, attitude, and practice score as compared to married women $(13.58 \pm 5.14$ vs $9.12 \pm 4.04, \mathrm{p}<.001)$. Women with different levels of education had statically significantly different knowledge, attitude, and practice scores ( $\mathrm{p}<.001)$ (Tables 2-3).

\begin{tabular}{|c|c|c|c|}
\hline Marital status & $\mathrm{N}$ & Mean \pm SD & $p$-value \\
\hline Married & 288 & $9.12 \pm 4.04$ & \multirow{2}{*}{$<.001$} \\
\hline Unmarried & 306 & $13.58 \pm 5.11$ & \\
\hline
\end{tabular}

TABLE 2: Comparison of knowledge, attitude, and practice scores between married and unmarried women

\begin{tabular}{|l|l|l|l|}
\hline \hline Level of education & N & Mean \pm SD & P-value \\
\hline No formal education & 51 & $6.84 \pm 2.98$ & \\
\hline Primary & 81 & $9.17 \pm 5.01$ & $<.001$ \\
\hline Secondary & 78 & $8.15 \pm 4.02$ & \\
Higher secondary & 144 & $13.85 \pm 4.36$ & \\
\hline Graduate and above & 240 & $12.74 \pm 4.89$ & \\
\hline
\end{tabular}

TABLE 3: Comparison of knowledge, attitude, and practice scores among different levels of education

\section{Discussion}

The current study identified inadequate knowledge, attitude, and practice regarding cervical cancer. Similar results were revealed by a study done in India, where $64 \%$ of the respondents knew about one or more 
symptoms of cervical cancer and 39\% knew about the risk factors [8]. A Nigerian study also revealed low knowledge (43.5\% respondents) of cervical cancer screening [9]. Similar studies done in other developing countries showed similar results. For example, an Ethiopian study showed 9.9\% of the participants had undergone cervical cancer screening in their lifetime while a Cambodian study showed 34\% women had heard of cervical cancer and 7\% had a pap smear test [10-11]. Developing countries have a higher burden of cervical cancer ( $80 \%$ cases); poor knowledge, attitude, and practice may be a contributing factor in this scenario.

In the current study, we have observed higher knowledge among unmarried women as compared to married women. This might be due to the fact that unmarried women are relatively younger and have more interest in the potential source of information regarding cervical cancer, e.g. Internet and social media. Formal education may also play a role in increasing cervical cancer-related knowledge; this study revealed the lowest level of knowledge among those who had no formal education.

When comparing with the local (Pakistani) studies, we have found our current study showed slightly better knowledge and attitude among the respondents as compared to a previous study done in two public hospitals of Karachi, Pakistan [12]. Another previous Pakistani study found $2.6 \%$ of the respondents underwent a Pap smear test while the current study found 5.9\% underwent the test [13]. This suggests that the knowledge, attitude, and practice of cervical cancer in Pakistan is improving with time. Several studies in developed countries have concluded that even in the higher socio-economic strata of South Asian women, the rates of Pap test receipt remain low due to a lack of awareness [14-16]. Therefore, improving the knowledge of the population regarding cervical cancer screening is one of the most important steps in enhancing the Pap test coverage among Pakistani women.

\section{Limitation}

Being a single center study, it may not involve the sample representative of the population of the whole country. The reason behind low knowledge, attitude, and practice could not be established, as it was a crosssectional study.

\section{Recommendation}

Further, similar studies can be done to compare the results and understand the pattern of improvement of knowledge. Improvement in female education rates, open conferences regarding sexual health, and increasing information availability will eventually improve the attitude and practice toward cervical cancer screening.

\section{Conclusions}

Overall poor knowledge, attitude, and practice regarding cervical cancer is observed all over the developing world. This study showed a slightly higher knowledge as compared to previous Pakistani studies. More than two-thirds of women will undergo a Pap smear test if the service is given free of cost. Local authorities may run free Pap smear test centers to detect cervical cancer early and lower the nationwide cervical cancer burden.

\section{Additional Information \\ Disclosures}

Human subjects: Consent was obtained by all participants in this study. Animal subjects: All authors have confirmed that this study did not involve animal subjects or tissue. Conflicts of interest: In compliance with the ICMJE uniform disclosure form, all authors declare the following: Payment/services info: All authors have declared that no financial support was received from any organization for the submitted work. Financial relationships: All authors have declared that they have no financial relationships at present or within the previous three years with any organizations that might have an interest in the submitted work. Other relationships: All authors have declared that there are no other relationships or activities that could appear to have influenced the submitted work.

\section{References}

1. Ferlay J, Shin HR, Bray F, Forman D, Mathers C, Parkin DM: Estimates of worldwide burden of cancer in 2008: GLOBOCAN 2008. Epidemiology. 2010, 2:2893-2917. 10.1002/ijc.25516

2. Moodley I, Tathiah N, Mubaiwa V, Denny L: High uptake of gardasil vaccine among 9 - 12-year-old schoolgirls participating in an HPV vaccination demonstration project in KwaZulu-Natal, South Africa. SAMJ S Afr Med J. 2013, 103:318-321. 10.7196/samj.6414

3. Parkin DM, Bray F, Ferlay J, Pisani P: Global cancer statistics, 2002. CA Cancer J Clin. 2005, 55:74-108. 10.3322/canjclin.55.2.74

4. Batool SA, Sajjad S, Malik H: Cervical cancer in Pakistan: a review . J Pak Med Assoc. 2017, 67:1074-1077.

5. Pap smear: the life-saving test. (2014). https://tribune.com.pk/story/790620/pap-smear-the-life-savingtest/.

6. Khan S, Jaffer NN, Khan MN, et al.: Human papillomavirus subtype 16 is common in Pakistani women with 


\section{Cureus}

cervical carcinoma. Int J Infect Dis. 2007, 11:313-317. 10.1016/j.ijid.2006.06.007

7. Khan TM, Buksh MA, Rehman IU, Saleem A: Knowledge, and perception towards human papillomavirus among university students in Pakistan. Papillomavirus Res. 2016, 2:122-127. 10.1016/j.pvr.2016.06.001

8. Bansal AB, Pakhare AP, Kapoor N, Mehrotra R, Kokane AM: Knowledge, attitude, and practices related to cervical cancer among adult women: a hospital-based cross-sectional study. J Nat Sci Biol Med. 2015, 6:324328. 10.4103/0976-9668.159993

9. Ahmed SA, Sabitu K, Idris SH, Ahmed R: Knowledge, attitude and practice of cervical cancer screening among market women in Zaria, Nigeria. Niger Med J. 2013, 54:316-319. 10.4103/0300-1652.122337

10. Aweke YH, Ayanto SY, Ersado TL: Knowledge, attitude and practice for cervical cancer prevention and control among women of childbearing age in Hossana town, Hadiya zone, Southern Ethiopia: communitybased cross-sectional study. PloS One. 2017, 25:0181415. 10.1371/journal.pone.0181415. eCollection 2017

11. Touch S, Oh JK: Knowledge, attitudes, and practices toward cervical cancer prevention among women in Kampong Speu Province, Cambodia. BMC Cancer. 2018, 18:294. 10.1186/s12885-018-4198-8

12. Razzaq S, Sayed SA, Ali SA: Knowledge and awareness regarding cervical cancer and uptake of pap smear among women in Karachi, Pakistan. EC Gynaecology. 2017, 4:154-161.

13. Imam SZ, Rehman F, Zeeshan MM, et al.: Perceptions and practices of a Pakistani population regarding cervical cancer screening. Asian Pac J Cancer Prev. 2008, 9:42-44.

14. Chaudhry S, Fink A, Gelberg L, Brook R: Utilization of Papanicolaou smears by South Asian women living in the United States. J Gen Intern Med. 2003, 18:377-384. 10.1046/.1525-1497.2003.20427.x

15. Gupta A, Kumar A, Stewart DE: Cervical cancer screening among South Asian women in Canada: the role of education and acculturation. Health Care Women Int. 2002, 23:123-134. 10.1080/073993302753429004

16. Sutton GC, Storer A, Rowe K: Cancer screening coverage of South Asian women in Wakefield . J Med Screen. 2001, 8:183-186. 10.1136/ims.8.4.183 